\title{
Percent Recovered Normalized by Dose
}

National Cancer Institute

\section{Source}

National Cancer Institute. Percent Recovered Normalized by Dose. NCI Thesaurus. Code C92414.

The percentage of the dose that is recovered from the specimen type, from dosing to end of the current collection interval divided by the dose. 